nerve fibre-calibre in clinical cases of toxic amblyopia where the macular bundle is mainly affected, or in experimental lesions of the macula, and also a comparative study of the normal histograms in a series of primates and sub-primates, should throw further light on the subject; work along these lines is in progress.

I wish to thank Prof. W. E. Le Gros Clark for encouragement and advice while carrying out this work.

\title{
REFERENCES
}

ALlison, A.C. and CHACKo,L. W. (1948).-Jl. Royal Microscopic. Soc. (In the Press) Brodal, A. and HARRISON, R. G. (1948).-Quart.Jl. Micr. Science, Vol. LXXXVIII, Series 3, No. 4 (In the Press).

Снаско, L. W. (1948).- Jl. Neurology, Neurosurgery and Psychiatry (In the Press).

Gudden, B. von (1886).-S. B. Ges. Morphol. Physiol., Münch., Vol. I, p. 169. Quoted by G. H. Bishop and J. O'Leary, Jl. Neurophys., Vol. III, 1940, p. 308.

Ḧ̈GGQUIST, G. (1936).-Z. Mikrosk. Anat. Forsch., Vol. XXXIX, p. 1.

(1937). - Ibid., Vol. XLlI, p. 1 .

Polyak, S. L. (1942).-The Retina. The University of Chicago Press.

Szentágothai-Schimert, J. (1941). -Z.f. Anat. u. Entwick. Gesch., Vol. CXI, p. 201.

Young, J. Z, (1945).-Essays on Growth and Form, Ed. by W. E. Le Gros Clark and P. B. Medawar. Oxford Univ. Press.

\section{ACUTE RETINOPATHY WITHOUT HYPERPIESIS IN DIABETIC PREGNANCY*}

BY

\author{
R. D. LAWRENCE
}

OF THE DIABETIC DEPARTMENT, KING'S COLLEGE HOSPITAL,

LONDON

I HAVE recently seen acute haemorrhagic retinopathy in two pregnant diabetic women such as has not hitherto been described. Retinopathy is all too common in long-standing diabetes, but is a slow process with characteristic venous haemorrhages and exudates developing slowly ovèr years, although a form which quickly develops into retinitis proliferans is occasionally seen. The severe toxaemia of pregnancy too produces an acute retinopathy with oedema, papillitis, severe haemorrhages, " albuminuric " in nature and appearance, always associated with hypertension, albuminuria and toxaemia. The following two cases fall into neither of the above categories, have not been described in ophthalmology or diabetic literature and presented a novel problem as to the termination of these pregnancies. The condition must be very rare and I have seen it in only 2 of some 200 diabetic pregnancies closely followed and is so striking in visual defect that I could not have missed other such cases.

- Received for publication, March 19, 1948. 
CASE 1. A very long-standing case who developed diabetes at age of 11 years in 1924, had insulin for 19 years before her pregnancy in 1943 at the age of 30 years. She was a spirited and clever young woman who led the wildest of diabetic lives, travelling all over the world on insulin varying from 20 to 80 units a day,

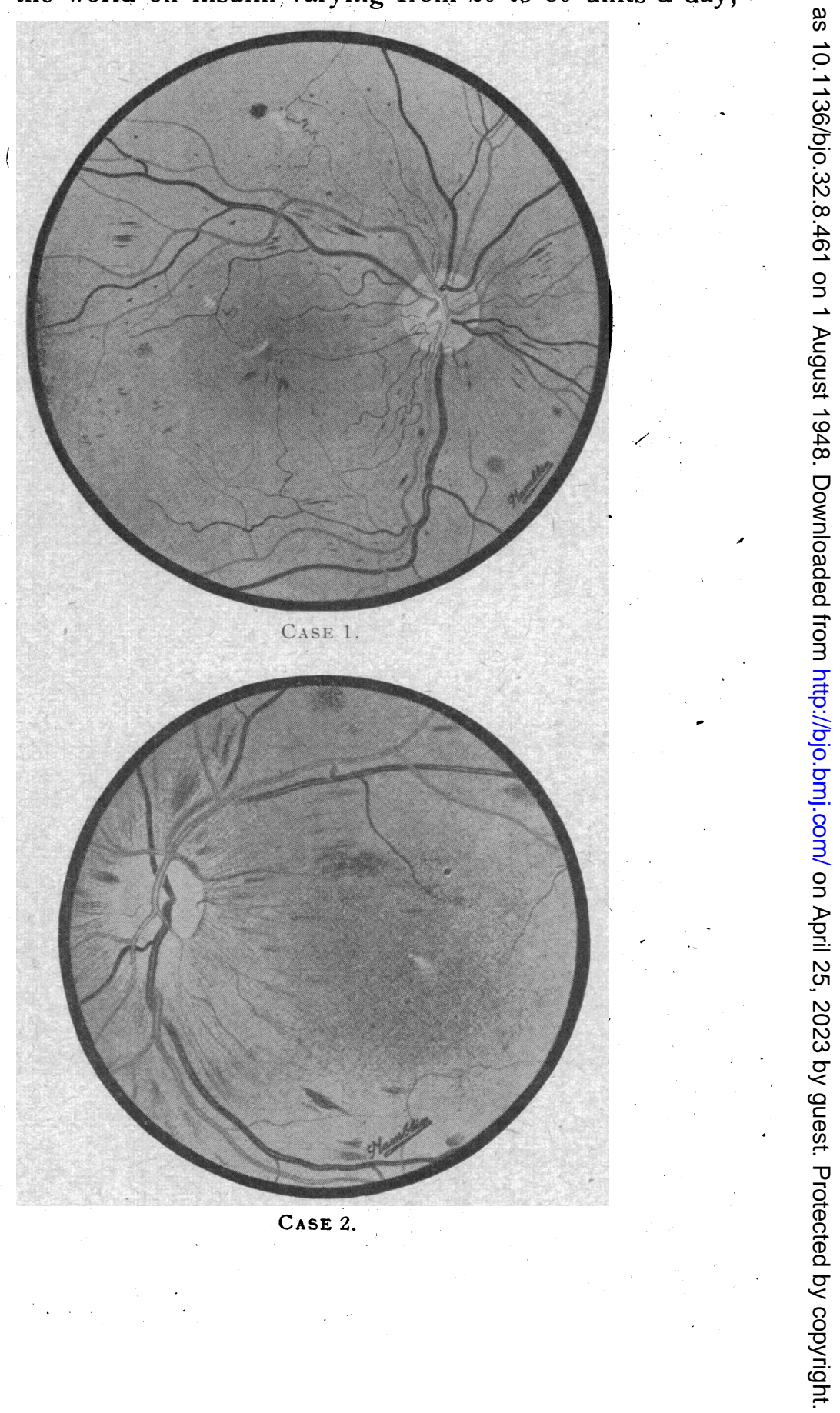


often loaded with sugar and ketones, precomatose from short supplies of insulin in the Tropics and a perfect candidate for retinal and other complications which long-standing and especially uncontrolled diabetes often brings. Married in 1942, after a miscarriage at 3 months, she again became pregnant and when seen at 10 weeks determined to co-operate in every way and rest and progesterone were followed. Her eye grounds and general physical state were normal. At 20 weeks, after a few days of mild sickness and vomiting, misty vision developed and when she was admitted for observation at the 23rd week, severe haemorrhagic retinopathy and a little exudate were obvious. Mr. Savin's notes gave the following details (December 1943). " Very extensive bilateral retinopathy with macular oedema and some exudate at L. macula. There are numerous flame-shaped and circular retinal haemorrhages. The vessels do not seem badly affected; no swelling of the discs. This is a serious haemorrhagic retinopathy. I could not be at all sure ophthalmoscopically if it were diabetic in origin and have no experience of the effect (nor necessity) of terminating pregnancy." (See Fig. 1.) Several other physicians and ophthalmologists confessed their ignorance. I had expected perhaps some renal toxaemia, but every urinary and blood test was normal (blood pressure $110 / 70$ as always). After this her vision improved a little but when seen at the 30th week, her eye grounds were the same except for less macular oedema. After this, war conditions made London difficult and a healthy child was produced by Caesarean section in her home town at the 37 th week. Her vision improved (" normal," she said) but one year' later (1945) I saw two typical diabetic punctate haemorrhages, a big dilated venule, a small white exudate and some fading haemorrhages at the right macula. After another year (April, 1946) a report from Mr. N. P. R. Galloway said that although her vision is $6 / 6,6 / 5$, her right fundus shows fine vitreous veils like commencing retinitis proliferans and the left, a few punctate haemorrhages, typical of diabetic trouble. Before this she again became pregnant, but abortion was induced. So a retinopathy still persisted, seemingly diabetic. When examined 18 months later, however, 5 years after the original lesion, the fundi were entirely normal.

CASE 2 had a very similar early history. Diabetes began at the age of 10 years in 1930, much insulin-60-80 units-often too much food and gross obesity. First pregnancy in 1943, normal child by Caesarean section, normal eyes.

A second pregnancy (1946) began normally and the eye grounds remained normal until " influenza " with 4 days' severe vomiting eccurred at the 28th week, followed at once by "misty and spotty" vision. When seen a week later an intense haemorrhagic retino- 
pathy was present and Mr. Savin reported: " She has a severe bilateral haemorrhagic retinopathy with numerous flame-shaped and deep haemorrhages and a little exudate. The peripheral arteries are in many instances narrowed and in a state of spasm. Discs normal. In my view this is a toxic condition rather than the type usually associated with diabetic retinopathy." However, all tests for toxaemia in blood and urine were normal, blood pressure $110 / 60$, very slight anaemia, B.S.R. $34 \mathrm{~mm}$./1st hour. RH factor positive, no atypical antibody. Arm capillary fragility normal. Altogether nothing abnormal was found except the diabetes. Vitamin $\mathrm{K}$ and $B_{1}$ were given in large doses. In the next weeks bilateral Bell's Palsy developed and the retinopathy became slightly worse (see picture by Messrs. Hamblin). Nausea and occasional vomiting continued. Termination was most seriously considered, but the mother instinct settled our problem by refusal. The vision fluctuated for better and worse, more haemorrhages, more and less oedema.

After Caesarean section at the $32 \mathrm{nd}$ week the vision became " normal " within a week and we watched the haemorrhages fade. Six months later Mr. Savin reported "the retinae and vessels are normal apart from some faint pigmentary patches and 1 or 2 crystalline deposits, relics of previous haemorrhages. But all this is a mere trifle."

I, however, saw one deep punctate haemorrhage, to me typically diabetic, in the left eye ground. But all the acute haemorrhagic process had certainly gone and the eye grounds had returned practically to normal. A year later the fundi were normal.

\section{Discussion}

I have not been able to find any similar published cases. In contrast I have followed 3 pregnancies in 2 diabetic women who previously had slight retinopathy, a few haemorrhages and fleck exudates, and the course of pregnancy made no difference to their retinal condition. Also I have followed about 12 diabetic pregnancies complicated with renal toxaemia, usually mild, which showed no retinal changes.

The only common factor in these two pregnancies different from many similar long-standing cases was unusual vomiting. This certainly raises the venous pressure and might well put the extra rupturing strain on the venules which are known to be the weak point in the diabetic retinal system. It is to be remembered also that the intra-ocular pressure is certainly reduced by dehydration, this diabetic disturbance being present in all such states of vomiting in severe insulin cases. But even if these two factors are causal ones in this retinopathy, it is hard to see why the condition should 


\section{Meguire General Hosp \\ Crater-like Holes in the Optic Disc \\ 465}

persist almost unchanged until delivery. So perhaps it is wise to report these two cases without explanatory hypothecation.

\section{Summary}

Two cases of acute and severe haemorrhagic retinopathy are described in pregnant diabetic 'women. The condition does not conform either to usual diabetic or to toxic renal retinopathy and the latter was excluded.

I am indebted to Mr. L. H. Savin for close study and reports on the retinal changes.

\section{CRATER-LIKE HOLES IN THE OPTIC DISC*}

\section{BY}

\section{Emanuel Rosen}

NEWARK, N.J.

Although Duke-Elder ${ }^{1}$ has stated that the condition known as " pits " or " crater-like holes in the optic disc" is of relatively frequent occurrence, yet Greear ${ }^{2}$ has been able to collect and tabulate only seventy-two cases including his three cases, the only three he had encountered in eighteen years of active practice. There would seem to be sufficient reason to report any additional cases and possibly in so doing to lend statistical support to the presentday concept of the condition without the necessity of awaiting pathological studies before one can be sure of the nature of this anomaly ${ }^{3}$.

CASE 1. This 31-year-old patient was examined routinely prior to embarkation. His vision was $20 / 20$ in each eye and his only ocular complaint was difficulty in reading for prolonged periods. There were no abnormal eye findings other than those of the right disc (Fig. 1). This disc was ovoid in shape with a thin, pigmented scleral ring on the temporal side. There was present a small physiological cup about $1 / 3$ D.D. in size located slightly upward and nasally. The cup was about three dioptres in depth and presented a pronounced cribriform plate at its bottom. Just nasal to the physiological cup was a triangular-shaped " pit" with its apex pointing inferiorly. This " pit" did not reach quite to the edge of the disc nor to the nasal edge of the physiological cup. The " pit " appeared to be blue-grey in colour and seven or eight dioptres in depth. A thin connective tissue veil seemed to be present within the cup rendering it difficult to visualize the bottom

* Received for publication, March 4, 1948. 